Contents list available at Multidisciplinary Journal website Multidisciplinary Journal

Journal homepage: https://jurnal.unej.ac.id/index.php/multijournal

\title{
Ketidaktepatan Kode Sebab Dasar Kematian menjadi Penyebab Kerugian 600 Juta Dana di Unit ICCU RSUD dr Moh Saleh Probolinggo
}

\author{
Inaccuracy of Code Underlying Cause of Death as a cause of 600Million Fund loss in the ICCU Unit of Dr. \\ Moh Saleh hospital Probolinggo \\ Novitasari ${ }^{1}$, Dewi Rokhmah ${ }^{2}$, Isa Ma'rufi ${ }^{3}$, \\ ${ }^{1}$ Master of Public Health Education, Jember University, East Java (Indonesia) \\ ${ }^{2}$ Public Health Lecturer, Faculty of Public Health Education, Jember University, East Java (Indonesia) \\ ${ }^{3}$ Public Health Lecturer, Master of Public Health Education, Jember University, East Java (Indonesia) \\ E-mail: novitabadriya@gmail.com
}

\begin{abstract}
ABSTRAK. Kode diagnosa penting sebagai bentuk gambaran perawatan pasien dalam manajemen rumah sakit dan penelitian, namun akurasi pengkodean merupakan masalah utama dalam proses diagnosis dan pengaruhnya terhadap tingkat pendapatan rumah sakit. Penelitian ini terkait dengan pengaruh ketidaktepatan kode penyebab dasar kematian terhadap tingkat pendapatan rumah sakit. Metode: Deskriptif dengan mengalisis keakuratan diagnosis sesuai dengan kode kematian yang disusun dalam Intruction Coding Manual of World Health Organization (WHO), setelah itu dilakukan persentase kerugian dalam sistem INAcbg's. Hasil : Sebanyak 176 berkas rekam medis yang diteliti, 114 berkas rekam medis atau 65\% kode diagnosis penyebab kematian tidak tepat, 57 berkas rekam medis atau 32\% dikode dengan tepat, 5 berkas rekam medis atau 3\% berkas rekam medis tidak dikode. 114 berkas rekam medis atau 65\% berkas yang tidak tepat tersebut berkontribusi terhadap kerugian rumah sakit sebesar 40-75\% dengan total kerugian yang diterima rumah sakit sebesar Rp. 597.849.006 atau hampir 600juta rupiah. Kesimpulan : tidak tepatnya diagnosis kematian meningkatkan kerugian rumah sakit lebih dari $40 \%$ hingga $75 \%$
\end{abstract}

Kata Kunci: Akurat, Kode Penyebab Dasar Kematian, ICD 10

\begin{abstract}
The coding of the diagnosis is important for patient care, hospital management and research. However, coding accuracy is a major problem in the diagnosis process and has impact on hospital income levels. This study is about the inaccuracy of the underlying cause of death coding toward the level of hospital income. The Methods employed is the Analysis of the accuracy of the diagnosis according to the mortality coding rules compiled in the Instruction Coding Manual of the World Health Organization (WHO). Afterwards, the percentage of losses is calculated using the system of INAcbg's, in the Diagnosis Based on Indonesian Case system. The result shows that, out of 176 files were studied, 114 files or $65 \%$ of the diagnosis codes of the cause of death were incorrect, 57 files or 32\% were correct and 5 files or $3 \%$ of files were not coded. Further, the study found out that $65 \%$ of these inaccuracies contributed to hospital losses which includes $40-75 \%$ loss with the total loss received by the hospital as much as IDR 597,849,006 or nearly 600 million rupiah. The research concludes that the absence of a diagnosis of death increases hospital losses by more than $40 \%$ to $75 \%$.
\end{abstract}

Keywords: Accuracy, Code of Basic Cause of Death, ICD 10

\section{Pendahuluan}

Rumah sakit institusi pelayanan kesehatan yang menyelenggarakan pelayanan kesehatan secara perorangan maupun kesehatan komunitas, secara paripurna yang menyediakan pelayanan rawat inap, rawat jalan dan gawat darurat (Kemenkes,2009).

Rekam medis berisikan catatan dan dokumen tentang identitas pasien, pemeriksaan, pengobatan, tindakan dan pelayanan lain yang diberikan kepada pasien. Pelayanan kesehatan tidak akan berjalan dengan baik tanpa didukung oleh pelayanan rekam medis yang terdiri dari bagian assembling, coding, indexing, analizing, reporting, dan filing.

Bagian coding memiliki tugas penetapan kode diagnosis penyakit sesuai dengan aturan pengkodean ICD-10 yang telah ditetapkan oleh WHO termasuk koding kematian. Koding kematian ditulis di sertifikat kematian yang ditandatangani 
oleh dokter DPJP atau penanggungjawab yang menentukan kondisi sakit yang langsung maupun tidak langsung terhadap kematian dan menyatakan kondisi awal yang menimbulkan sebab kematian.

Sertifikat kematian berisi runtunan kejadian yang menyebabkan kematian. Diagnosisyang dituliskan harus lengkap dan konsisten untuk memudahkan coder dalam mengkode penentuan diagnosis sebab dasar kematian. Penyebab dasar kematian adalah sebab-sebab kematian sebagai semua penyakit, keadaan sakit atau cedera yang menyebabkan atau berperan terjadinya kematian (Hatta, 2013).

Penentuan penyebab dasar kematian dapat menggunakan ICD-10 untuk mengkode diagnosis penyakit dalam sertifikat kematian kemudian dilakukan penetapan diagnosa sesuai aturan kodefikasi untuk mempermudah penetapan kode UCoD (Underlying Cause of Death) yang benar dan penentuan kode penyebab multipel yang tepat.

Kode penyebab dasar kematian yang telah ditetapkan akan digunakan sebagai landasan untuk menyusun pelaporan statistik kematian berupa angka harapan hidup, angka kematian menurut penyebab dan umur yang akan digunakan untuk melihat status kesehatan masyarakat dan sebagai bahan pertimbangan untuk mengambil keputusan terkait dengan upaya pencegahan dari penyakit (preventif primer).

Dokter harus menggunakan pertimbangan klinis dalam melengkapi diagnosis dalam sertifikat kematian agar penentuan kode sebab dasarkematian oleh coder menjadi tepat dan akurat (Sarimawar dan Suhardi, 2008)

\section{Bahan dan Metode}

Penelitian ini penelitian deskriptif dilakukan dengan metode pengambilan data secara observasi dan wawancara. Pendekatan studi retrospektif. Penelitian ini bertempat di RSUD dr Moh Saleh pada tahun 2019. Sampel penelitian ini diambil secara systematic random sampling dengan jumlah sampel 176 dokumen. Analisis data dengan analisis deskriptif. Penyajian data menggunakan tabel dan grafik.

\section{Hasil dan Pembahasan}

a. Analisa Ketepatan Kodefikasi Kematian 176 berkas Rekam Medis

\begin{tabular}{llcl}
\cline { 2 - 4 } $\mathrm{e}$ & \multicolumn{1}{c}{ Tingkat Pengisian } & Jumlah & \multicolumn{1}{c}{$\%$} \\
\cline { 2 - 4 } $\mathrm{S}$ & tidak tepat tidak beruntun & 176 & $100 \%$ \\
\cline { 2 - 4 } $\mathrm{k}$ & tidak tepat tapi beruntun & 0 & $0 \%$ \\
\cline { 2 - 4 } $\mathrm{r}$ & tepat dan beruntun & 0 & $0 \%$ \\
\cline { 2 - 4 } $\mathrm{i}$ & Jumlah & 176 & $100 \%$ \\
\cline { 2 - 4 } $\mathrm{psi}$ & hasil analisa ketepatan & kodefikasi & diagnosa
\end{tabular}

kematian pada pengamatan 176 berkas rekam medis yang menjadi sampel penelitian disajikan pada beberapa tabel dan diagram berikut ini:

\section{Prosentase Ketidaktepatan Kodefikasi Kematian Penentuan Kode Penyebab Dasar (UCOD)}

Hasil penelitian dibawah ini memaparkan tentang tingkat prosentase ketidaktepatan kodefikasi kematian di instalasi ICCU RSUD dr Moh Saleh Probolinggo dalam tabel berikut ini Tabel 1.1 Prosentase Ketidaktepatan Kodefikasi Kematian Instalasi ICCU RSUD dr Moh Saleh Probolinggo

\begin{tabular}{lll}
\hline Tingkat Ketepatan & Jumlah & \% \\
\hline Berkas Tepat & 57 & $32 \%$ \\
\hline Berkas Tidak Tepat & 114 & $65 \%$ \\
\hline Berkas Tidak dikoding & 5 & $3 \%$ \\
\hline Jumlah & 176 & $100 \%$ \\
\hline
\end{tabular}

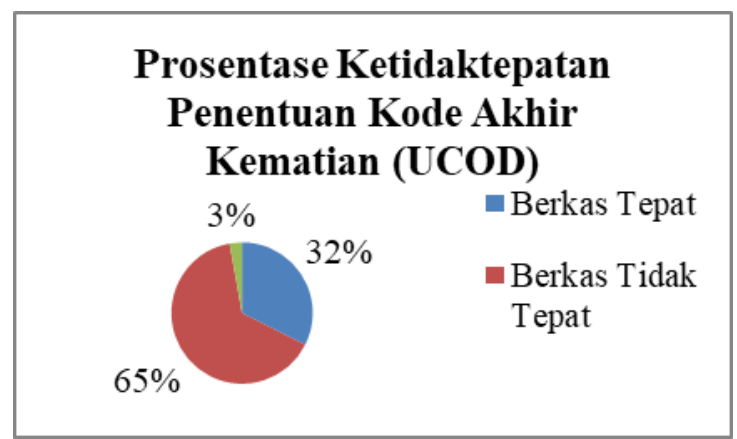

Sumber : Data Primer, 2020

Data diatas menunjukkan bahwa dari 176 berkas yang telah diteliti ditemukan sebanyak $65 \%$ atau sekitar 114 berkas kodefikasi diagnosa kematian yang ditetapkan tidak tepat, dan sebesar $32 \%$ atau sekitar 57 berkas yang diambil sampel kodefikasinya sudah benar, dan hanya 3\% saja yang kodefikasinya tidak dilakukan atau kosong.

\section{Prosentase Ketepatan Pengisian Sertifikat Kematian}

Hasil penelitian dibawah ini memaparkan tentang tingkat prosentase ketepatan pengisian sertifikat kematian di instlasi ICCU RSUD dr Moh Saleh Probolinggo dalam tabel berikut ini Tabel 1.2 Prosentase Ketepatan Pengisian Sertifikat Kematian Instalasi ICCU RSUD dr Moh Saleh Probolinggo

$$
\mathrm{S}
$$




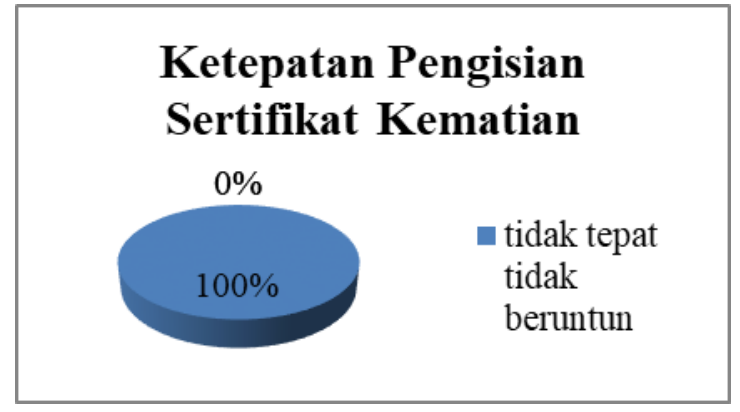

Sumber : Data Primer 2020

Data diatas menunjukka bahwa dari 176 berkas yang diambil samplingnya untuk dianalisa ketepatan pengisian sertifikat kematian seluruhnya $100 \%$ atau 176 berkas tersebut tidak terisi sertifikat kematiann internasional, artiya tidak dilakukan pengisian sertifikat kematian internasional sesuai yang ditetapkan WHO dalam pedoman penulisan rekam medis kematian pasien, sehingga tidak ada penulisan beruntun tentang penyebab dasar kematian pasien baik secara langsung maupun tidak langsung.

\section{Grouping Harga Kodefikasi Diagnosa Kematian dan Prosentase Kerugiannya}

Hasil penelitian dibawah ini memaparkan tentang hasil grouping harga kodefikasi diagnosa kematian dan kerugiannya di instlasi ICCU RSUD dr Moh Saleh Probolinggo dalam tabel berikut ini;

Tabel 1.3 Grouping Harga Kodefikasi Diagnosa Kematian dan Prosentase Kerugiannya

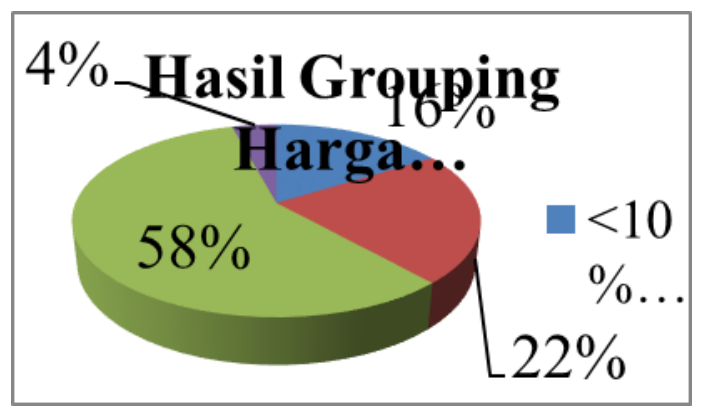

\begin{tabular}{lll}
\hline Prosentase Kerugian & Jumlah & $\%$ \\
\hline$<10 \%-19 \%$ & 27 & $16 \%$ \\
\hline $\begin{array}{l}\mathrm{S} 20 \%-39 \% \\
\mathrm{u}\end{array}$ & 37 & $22 \%$ \\
\hline $\mathrm{n} 40 \%-49 \%$ & 96 & $58 \%$ \\
\hline $\mathrm{b}_{>50 \%}$ & 7 & $4 \%$ \\
\hline $\mathrm{e}$ Jumlah & 176 & $100 \%$ \\
$\mathrm{r}$ & &
\end{tabular}

: Data Primer 2020

Data diatas menunjukkan bahwa hasil grouping inacbgs pada 176 berkas yang diteliti didapati kesimpulan bahawa sebanyak 58\% atau sejumlah 96 berkas yang dikoding diagnosa kematian jumlahnya mengalami kerugian tersebsar berada dalam prosentase kerugian sekitar 40-49\% dari harga asli yang seharusnya didapat, sedangkan sebanyak 7 berkas yang kodefikasinya tidak tepat mengalami kerugian lebih dari 50\% bahkan bisa sampai $75 \%$, total kerugian dari tahun 2018 hingga triwulan pertama tahun 2019 dari 176 berkas yang diteliti adalah sebesar Rp 597.849 .006

Hasil pemetaan kinerja koder dalam melakukan kodefikasi diagnosa dari 176 berkas yang diteliti bahwa sebanyak 57 berkas atau $32 \%$ saja berkas yang tepat diagnosa penyebab kematiannya, sedangkan $65 \%$ seluruh berkas atau sebanyak 114 berkas tidak tepat kodefikasi diagnosanya, dan 3\% sisanya adalah berkas yang tidak dilakukan kodefikasi diagnosa kematian, sedangkan dari penulisan sertifikat kematian sebanyak 176 atau 100\% sertifikat kematian tidak diisi, bahkan tidak tersedia berkas rekam medis sertifikat kematian,

Hasil ini menunjukkan bahwa kinerja koder dalam melakukan kodefikasi diagnosa kematian di unit ICCU masih belum maksimal.

Sejalan dengan penelitian ini, Yuniati, Dewi Indah (2012) menyatakan bahwa koder mempengaruhi penerimaan rumah sakit karena kemampuannya dalam menetapkan kode mengggunakan ICD untuk mengkode diagnosa dan prosedur yang tercatat didalam dokumen rekam medis, hasilnya kodefikasi yang salah sebanyak 32,6\% berpotensi menurunkan pendapatan rumah sakit rata-rata sebesar $4,2 \%$ dari klaim yang seharusnya diterima setiap 1 kasus pasien. 
Penelitian lain mengemukakan bahwa dari 86 sampel berkas rekam medis pasien operasi patah tulang yang diteliti, sebanyak $89,5 \%$ berkas tidak tepat, penyebab ketidaktepatan kodefikasi ini terjadi karena ketidakjelasan tulisan dokter yang tidak spesifik menuliskan posisi patah tulangnya, sehingga banyak kode yang tidak tepat (Rusliyanti, NKL et al 2016).

Dari penelitian ini juga digambarkan tentang pelayanan dan bukti pelayanan operasi yang dilakukan dokter bedah, karena dokter tidak pernah spesifik menyebutkan patah tulang yang tertulis di rekam medis bersifat terbuka atau tertutup, sedangkan kodefikasi jenis patah tulang sangat berpengaruh pada kode yang di inputkan dalam sistem pembiayaan dan menentukan tingkat kesulitan operasi atau severity level diagnosa, ketidakjelasan catatan ini menjadi gambaran dari mutu pelayanan yang diberikan karena berkaitan dengan asuhan dan pelayanan kesehatan yang sudah diberikan. (Hatta,2008) dan Abdelhak et al. dalam Pramono dan Nuryati (2012).

Perumusan diagnosa termasuk indikasi yang dipertimbangkan dalam mutu pelayanan rumah sakit sekaligus indikator kualitas pelayanan yang diberikan sesuai dengan standart dan etika profesi tenaga kesehatan yang memberikan pelayanan kepada pasien. (Batubara, Fitri 2019). Sistem kodefikasi dari diagnosis akhir dan tindakan/prosedur yang menjadi output pelayanan, berbasis pada data costing dan coding penyakit yang mengacu pada International Classification of Disease (ICD) yang disusun oleh WHO dengan acuan ICD 10 untuk diagnosa dan ICD 9 CM untuk tindakan atau prosedur, dengan adanya sistem kodefikasi yang terumuskan dalam sistem inacbgs yang merupakan sistem pembayaran prospektif untuk menggambarkan pelaksanaan pelayanan kesehatan yang berkualitas dan cost effective (Wa Ode, D W et al. 2015)

Artanto, Antonius (2018) meneliti tentang faktor faktor penyebab tertundanya klaim BPJS Kesehatan RSUD dr Kanujoso Djatiwobowo pada triwulan pertama tahun 2016, peneliti menemukan bahwa penyebab tertundanya klaim salah satunya hanya ketidaklengkapan resume medis termasuk penyebab kematian pasien sehingga sekitar 10$15 \%$ pembayaran klaim tertunda.

Sedangkan dari 176 berkas yang diteliti tidak ada satupun lembar pengisian sertifikat kematian yang terisi bahkan setelah ditelusur di unit rekam medis, didapati informasi bahwa selama ini rumah sakit tidak membuat berkas rekam medis sertifikat kematian yang sudah terstandarkan oleh World Health Organization (WHO) kematian hanya di catat di lembar keterangan kematian dan diserahkan ke pihak keluarga untuk diberikan di kelurahan dan kecamatan setempat.

Jadi selama ini belum ada proses kodefikasi dan reseleksi kodefikasi kematian di lembar sertifikat kematian. Maka prosentase pengisian sertifikat kematian $100 \%$ tidak terisi dan indikator ketidaktepatan dan ketidakberuntutan penentuan diagnosa Underlying Cause of Death (UCOD) adalah 100\%.

Ilmi, Laili R dan Zakharias (2020) melakukan penelitan pada 374 sertifikat kematian selama periode 2018 ditemukan bahwa hanya 55 sertifikat yang benar kodefikasi kematiannya, sisanya 311 sertifikat tidak tepat, kodefikasi yang tidak tepat tersebut berisiko informasi penyebab kematian yang tidak beruntun secara medis dan secara waktu kematian sehingga banyak informasi yang belum akurat dalam penyusunan laporan kematian.

Wahyuni, Titin dan Dyah Rachmadhani (2018) meneliti tentang pengaruh kelengkapan pendokumentasian sertifikat medis penyebab kematian terhadap akurasi penyebab dasar kematian didapati informasi bahwa sebesar $55,71 \%$ sertifikat kematian tidak akurat kodefikasinya hasil penelitian ini menyimpulkan bahwa penerapan penulisan sertifikat kematian tidak dilakukan sehingga dapat disimpulkan bahwa hampir sebagian besar dokter yang melakukan pengisian rekam medis tidak melakukan pencatatan medis dengan benar.

Penelitian ini mengemukakan beberapa permasalahan yang masih menjadi inti dalam pencatatan rekam medis dan kualitas penentuan diagnosa kematian terhadap kinerja koder dan petugas rumah sakit beberapa masalah tersebut antara lain :

1) Masih rendahnya tingkat pengetahuan petugas tentang proses penentuan diagnosa akhir hingga pencatatan kode diagnosa yang 
ditetapkan ruangan ICCU RSUD dr Moh Saleh Probolinggo,

2) Masih rendahnya tingkat kelengkapan dan kekonsistensian pencatatan rekam medis di ruangan ICCU RSUD dr Moh Saleh Probolinggo,

3) Tidak terdapatnya SOP pencatatan dan penulisan tatacara kodefikasi diagnosa penyebab kematian,

4) Tidak terdapatnya fasilitas buku ICD 10 maupun ICD 9 CM di ruangan ICCU RSUD dr Moh Saleh Probolinggo,

5) Tidak terdapat kegiatan pemantauan atau supervisi audit coding pada pelaksanaan penentuan kodefikasi penyebab kematian di ruangan ICCU RSUD dr Moh Saleh Probolinggo,

6) Tidak terdapat pengisian lembar sertifikat kematian di RSUD dr Moh Saleh Probolinggo,

7) Indikator ketepatan dan keberuntunan penulisan dalam pengisian sertifikat kematian di RSUD dr Moh saleh Probolinggo $100 \%$ tidak tepat dan tidak berurutan.

Dari beberapa permasalahan diatas maka diperlukan adanya beberapa solusi kongkrit yang harus dilakukan untuk menunjang terlaksananya standart operasional prosedur pencatatan rekam medis hingga upaya peningkatan kualitas pelayanan dan kinerja, yakni :

1. dilakukan minilokakarya dan workshop terkait pencatatan rekam medis elektronik maupun rekam medis manual,

2. melakukan pengajuan pembuatan resume online berbasis android untuk dokter melengkapi resume medis dan catatan perkembangan pasien terintegrasi,

3. menempatkan 1 perekam medis pada masingmasing unit ruangan untuk melakukan crosscheck dan pencatatan diagnosa akhir yang tepat

\section{Kesimpulan}

Sebanyak 176 file diteliti, 114 file atau 65\% kode diagnosis penyebab kematian salah, 57 file atau $32 \%$ benar, dan 5 file atau 3\% file tidak dikodekan, $65 \%$ di antaranya tidak akurat. memberikan kontribusi kerugian rumah sakit 40$75 \%$ kerugian dengan total kerugian yang diterima rumah sakit sebesar Rp 597.849.006 atau hampir 600 juta rupiah. Kesimpulan: tidak adanya diagnosis kematian meningkatkan kerugian rumah sakit lebih dari $40 \%$ sampai $75 \%$

\section{Acuan Referensi}

1. Ayub, S , Salvatore, T Scali, Richter Julie, Huber, Thomas et al (2017). Financial implications of coding inaccuracies in patient undergoing elective endovascular abdominal aortic aneurysm repair. Presented in the plenary session at the 2017 Vascular Annual Meeting of the Society for Vascular Surgery, San Diego, Calif, May 31-June 3, 2017https://doi.org/10.1016/j.jvs.2018.04.027

2. Rosen, Lisa. Tao Liu, Roland C M (2015). Efficiency of International Classification of Diseases, Ninth Revision, Billing Code Searches to Identify Emergency Department Visits for Blood or Body Fluid Exposures through a Statewide MulticenterDatabase. DOI: https://eresources.perpusnas.go.id:2182/10.1086/6 65722Published online by Cambridge University Press: 02 January 2015

3. Tsopra, R et all (2018). "The impact of three discharge coding methods on the accuracy of diagnostic coding and hospital reimbursement for inpatient medical care". International Jurnal of Medical Informatic. Sciencedirect.

https://doi.org/10.1016/j.ijmedinf.2018.03.015

4. Hatta, Gemala Rabiecah. 2013. Pedoman Manajemen Informasi Kesehatan di Sarana Pelayanan Kesehatan Edisi Revisi. Jakarta UIPress.

5. Kasanah dan Sudra. 2011. Analisis Keakuratan Kode Diagnosis PPOK Eksaserbasi Akut Berdasarkan ICD10 Pada Dokumen Rekam Medis Pasien Rawat Inap Di RSUD Sragen Triwulan II Tahun 2011. JurnalKesehatan Vol 5 (1):72-78.

6. Keputusan Menteri Kesehatan Republik Indonesia. 2005. Keputusan MenteriKesehatan Republik Indonesia Nomor 496 Tahun 2005 Tentang Pedoman Audit Medis Di Rumah Sakit. Jakarta: Menkes RI.

7. Kresnowati dan Ernawati. 2013. Analisis Faktor-Faktor Yang Mempengaruhi Akurasi Koding Diagnosis Dan Prosedur Medis Pada Dokumen Rekam Medis Di RumahSakit Kota

Semarang.Semarang:Universitas Dian Nuswantoro.Laporan Akhir.

8. Kusumastuti, Suryaningrum. 2014. PengaruhPembuatan Standar Operasional ProsedurTerhadap Kinerja Karyawan BagianProduksi Di PT Wangsa Jatra Lestari. Surakarta: Universitas Muhammadiyah

Surakarta. Naskah Publikasi.

9. Ningrum dan Widjaya. 2016. Hubungan Kelengkapan Sertifikat Medis Penyebab Kematian Terhadap Ketepatan Kode Diagnosa Penyebab Kematian pasien Di Rumah Sakit Sumber Waras Jakarta Tahun 2016. Jurnal INOHIM Vol 4 (2): 58-62

10. Nuryati dan Hidayat. 2014. Evaluasi Ketepatan Kode Diagnosis Penyebab Dasar Kematian Berdasarkan ICD10 Di RS Panti Rapih Yogyakarta. Jurnal Manajemen InformasiKesehatan Indonesia Vol 2 (1): 82-89

11. Peraturan Menteri Kesehatan Republik Indonesia. PERMENKES RI Nomor 269/ MENKES/ PER/ III/ 2008 Tentang Rekam Medis. Jakarta: Menkes R

12. Peraturan Menteri Kesehatan Republik Indonesia. PERMENKES RI Nomor 55 Tahun 2013 Tentang Penyelenggaraan Pekerjaan Perekam Medis. Jakarta: Menkes RI

13. Peraturan Presiden Republik Indonesia. 2015. Peraturan Presiden Republik Indonesia Nomor 77 Tahun 2015 Tentang Pedoman Organisasi Rumah sakit. Jakarta: PresidenRI

14. Sarimawar dan Suhardi. 2008. Buku 
Menurut ICD-10. Jakarta: Badan Penelitiandan

Pengembangan Kesehatan Departemen Kesehatan RI

15. Undang-Undang Republik IndonesiaNomor 44 Tahun 2009 TentangRumahSakit.

Jakarta: Presiden RI

16. World Health Organization. 2010. InternationalStatistical Classification Of Diseases AndRelated Health Problem (ICD-10, Volume2). Geneva

17. Farzandipour M, Sheikhtaheri A, Sadoughi F (2010). Effective Factors on Accur-acy of Principal Diagnosis Coding Based on International Classification of Diseases, The 10th Revision (ICD-10). International Journal of Information Management. 30: 78-84 doi:10.1016/j.ijinfomgt.2009.07.002

18. Rangachari, P. (2007). Coding for quality measurement: The relationship between hospital structural characteristics and coding accuracy from the perspective of quality measurement [online]. Perspectives in Heath Information Management, 4. Available from: www.ahima.org/perspectives Accessed 10.05.08

19. O’Malley, K. J., Cook, K. F., Price, M. D., Wildes, K. R., Hurdle, J. F., \& Ashton, C. M.(2005). Measuring diagnoses: ICD code accuracy. Health Services Research, 40, 1620-1639

20. Sheikhtaheri, A and Merhrdad F (2009). Evaluation of factors Influencing Accuracy of principal Prosedure Coding Based on ICD 9 CM: An Iranian Study. Perspective in Health Information Management. 2009 Vol.6

21. O’Malley, K. J., Cook, K. F., Price, M. D., Wildes, K. R., Hurdle, J. F., \& Ashton, C. M.(2005). Measuring diagnoses: ICD code accuracy. Health Services Research, 40, 1620-1639.

22. Olli, Marsella W. 2018 "Analysis of Clinical Risk Management Implementation and Its Influencing Factors in Hospitals in Makassar. Universitas hasanuddin Makasar : 2018

23. Potter, P.,\&Perry, A. G. (1995). Basic nursing theory and practice (3rd ed.). USA: Mosby.Quan, H., Pearsons, G. A.,\&Ghali,W.A. (2004). Validity of procedure codes in international classification of diseases, 9th revision, clinical modification administrative data. Medical Care, 42, 801-809

24. World Health Organization. (2016). International statistical classification of diseasesand related health problems (Vol. 1) (10th ed.). Geneva: WHO.

25. World Health Organization. (2016). International statistical classification of diseasesand related health problems (Vol. 2) (10th ed.). Geneva: WHO.

26. World Health Organization. (2016). International statistical classification of diseasesand related health problems (Vol. 3) (10th ed.). Geneva: WHO

27. Surja`ın, G. (1999). Questions on validity of international classification of diseasescoded diagnoses. International Journal of Medical Informatics, 54, 77-95.

28. Tanuwidjaja,Gunawan. 2013. "Studi Fungsionalitas Fasilitas Jantung di RS X Surabaya" Universitas Kristen Petra. Surabaya : 2013

29. Utami, Yeni Tri. 2015. "Hubungan Pengetahuan Coder Dengan Keakuratan Kode Diagnosis Pasien Rawat Inap Jaminan Kesehatan Masyarakat Berdasarkan Icd-10 Di Rsud Simo Boyolali”. Infokes, Vol. 5 No. 1 Februari 2015 Issn : 2086 - 2628 